Chapman University

Chapman University Digital Commons

Education Faculty Articles and Research

Attallah College of Educational Studies

3-23-2016

\title{
Rediscovering Deep Time: Sustainability and the Need to Re-Engage With Multiple Dimensions of Time in Leadership Studies
}

Rian Satterwhite

International Leadership Association

Kate Sheridan

Carnegie Mellon University

Whitney McIntyre Miller

Chapman University,wmcintyr@chapman.edu

Follow this and additional works at: https://digitalcommons.chapman.edu/education_articles

Part of the Educational Leadership Commons, and the Leadership Studies Commons

\section{Recommended Citation}

Satterwhite, R., Sheridan, K. and McIntyre Miller, W. (2016), Rediscovering Deep Time: Sustainability and the Need to Re-Engage With Multiple Dimensions of Time in Leadership Studies. J Ldrship Studies, 9: 47-53. doi: 10.1002/jls.21426

This Article is brought to you for free and open access by the Attallah College of Educational Studies at Chapman University Digital Commons. It has been accepted for inclusion in Education Faculty Articles and Research by an authorized administrator of Chapman University Digital Commons. For more information, please contact laughtin@chapman.edu. 


\section{Rediscovering Deep Time: Sustainability and the Need to Re-Engage With Multiple Dimensions of Time in Leadership Studies}

\section{Comments}

This is the accepted version of the following article:

Satterwhite, R., Sheridan, K. and Miller, W. M. (2016), Rediscovering Deep Time: Sustainability and the Need to Re-Engage With Multiple Dimensions of Time in Leadership Studies. J Ldrship Studies, 9: 47-53. doi: $10.1002 / \mathrm{j} 1 \mathrm{s.} 21426$

which has been published in final form at DOI: $10.1002 / \mathrm{jl}$.21426.This article may be used for noncommercial purposes in accordance with Wiley Terms and Conditions for Self-Archiving and may not exactly replicate the final published version.

\section{Copyright}

University of Phoenix 


\section{Rediscovering deep time: Sustainability and the need to re-engage with multiple dimensions of time in leadership studies}

\section{Rian Satterwhite, Katherine Sheridan, and Whitney McIntyre Miller}

\section{Sustainability, Peace and Deep Time}

Our world is full of wicked challenges that shape the leadership context of the 21st century (Grint, 2010). Two such challenges, sustainability and peace, can be seen not as discrete wicked challenges, but rather as essential and interrelated frameworks from which to view all leadership challenges. Sustainability and peace are crucial components to integrate in effective leadership theory, practice, education, and development that prepares learners for the world we are collectively creating (Satterwhite, McIntyre Miller, Sheridan, 2015). Over the last decade, we have seen a rise in the scholarly discussion of sustainability and leadership, which in many ways inspired this current volume. Moving forward, all leadership endeavors should seek to understand and work within the need for sustainability and peace (Satterwhite, et. al., 2015). This stance, however, is not enough. In this paper, we build upon the argument that sustainability and peace are fundamental frameworks for effective leadership moving forward, and make the case that extended timescales - both extending into the future and the past - are also essential to leadership. We offer a loose structure of four dimensions of time - present, near, distant, and deep time - to help advance this work, and find that sustainability provides a particularly useful pathway to effectively engaging with deep time.

Much of the leadership studies literature focuses on leadership in the present, or the widely used concept of the near future, which may be five to ten years from now. We too frequently fail in thinking about the broader impact of our leadership work for generations to come, and grounding that work in our extended, collective history. In order to think about leadership utilizing a framework of sustainability and peace, it is essential that we critically examine our relationship with time and better incorporate it into our leadership theory, practice, development, and education. Time is commonly experienced as a two 
directional system, extending from the present, flowing from the past. The challenge is that we frequently limit our reach when extending into the future and staying connected to our past. We need to develop these muscles more, to enhance our ability to relate to and make sound decisions based on an informed consideration of the futures we wish to create and the deep histories that have led us to where we are now. We argue that this requires a fundamental shift in - as Scharmer and Kaufer (2013) frame - our relationship with ourselves, each other, and nature and the planet.

\section{Definitions/Descriptions of Time}

Time has for too long been relegated to the backseat in leadership theory and practice, and it is essential that an expanded understanding of time become a central concern, especially as we begin to acknowledge sustainability and peace as essential leadership constructs. In our day-to-day, we often frame time in terms of a simplistic short and long term, which fails to grasp the nuanced complexity and depth of time. This means re-discovering long timescales and moving to a state of operating more fully within the expanse of time available to us (Figure 1). In this section, we discuss a new framework that enables us to operate across four dimensions of time: present, near, distant, and deep time.

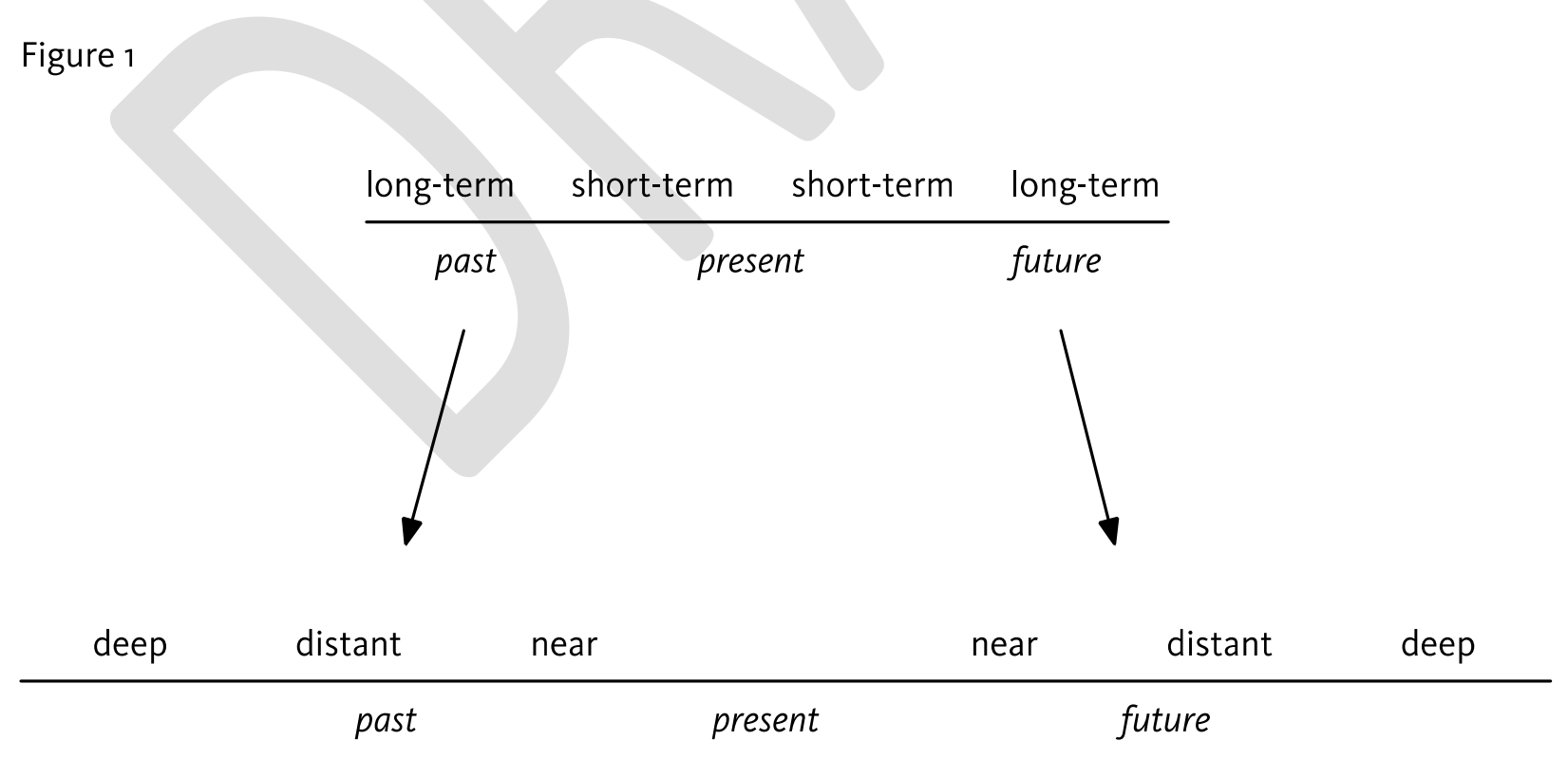


It is important to note that any boundary is, from a systems perspective, necessarily an artifice of our own creation; that boundaries are necessary for sanity and clarity, but that we too often take them to be innate by forgetting that we made them (Meadows, 2008). So let us proceed with the clear acknowledgement that these four dimensions are artificial constructs, but hopefully useful ones. It is also important to note that we see time as moving in both directions from the present. Not only do we fail to look at distant and deep time in the future, we frequently fail to learn from the past, especially the forgotten distant and deep past. The noted economist Kenneth Boulding wrote in 1966, “There is a great deal of historical evidence to suggest that a society which loses its identity with posterity and which loses its positive image of the future loses also its capacity to deal with present problems...” (as cited in Meadows, 2008, p. 182). In the section below we describe each dimension of time in more detail and reflect on the notion of each dimension of time both in the past and the future.

The time dimension most familiar to many of us is what we call present time. This is the dimension of time in which we typically operate and plan - from today through about five years from now- sometimes extending into the recent past. This is the time dimension inclusive of what we commonly call the shortterm. Derek Parfit (as cited in Frederick, Loewenstein, and O’Donoghue, 2002) suggests that, "We care less about our further future... because we know that less of what we are now - less, say, of our present hopes or plans, loves or ideals - will survive into the further future... [if] what matters holds to a lesser degree, it cannot be irrational to care less” (p. 359). Yet we pay the price of this rationality daily.

The next time dimension, extending on either side of present time, is what we call near time. Near time may be thought of as flowing directly prior to and following from present time, and could be considered inclusive of the commonly understood phrase 'long-term,' or, approximately, five years to several decades (commonly within our lifetime). We typically enter into this time dimension through questions of family, legacy, values, and purpose. 
Flowing in extended directions on either side of near time is the dimension we call distant time. Distant time is a time period roughly equivalent to an individual's lifetime, stretching approximately 80-100 years, possibly spanning into a few generations, but rarely further. Family, legacy, values and purpose similarly bridge us into these more distant futures and pasts. But we often struggle to find a grip on such slippery terrain, where uncertainties blur our vision and concrete examples of the future seem difficult to grasp.

Finally, flowing from distant time is what is sometimes called deep time. It bookends the time spectrum, holding the biological and cosmological truths of the past and the most distant hopes and fears of the future. Deep time is a multi-generational time and is easily the most difficult timescale to hold in our minds. It is more than just our grandchildren's time... deep time is inclusive of the commonly-cited seven generation perspective, but necessarily extends much further when geological, evolutionary, or cosmic timelines are introduced (see Gould, 1987; Benford, 1999; Smail, 2008; Capra and Luisi, 2014; Wilson, 2014). Deep time is typically used to describe the deep past, but it can also be used to envision distant futures. We believe that the field of leadership can stand to benefit from both.

The leadership challenges that shape our lived experience today have timelines extending many generations into the future, while being shaped by the many generations of the past. Unfortunately, we often fail to account for either. We must expand our comfort with deep history and deep futures. How can leadership theory, practice and education effectively adapt to this new reality? How can we begin to rediscover the wisdom of the past, pair it with the emerging knowledge of the present, to better shape and adapt to the challenges of the future? The remainder of this paper will visit these questions by utilizing the four dimensions of time presented here.

\section{Time and Leadership Studies}


Historically, leadership studies theory and literature has operated primarily in present and near time, with some applications into distant time. Perhaps most analogous in the leadership studies literature of what we would call present and near time is Heifetz's (1994) work on framing technical challenges- those that have known responses or can be solved through applying existing knowledge. Many of our present time challenges are those that can be addressed using technical solutions. In some cases, technical solutions can also be used to address problems operating in near time. Many of our leadership challenges, particularly when operating from a lens of sustainability and peace, require more than technical fixes to successfully build our world anew. Leadership theory has already helped illuminate the limitations of technical fixes. Concepts such as adaptive work, chaos and complexity theory, and systems thinking already have proven useful in sustainability leadership. In this section we provide a quick tour of these theories while adding into them the essential discussion of the element of time.

\section{Adaptive Work}

Another contribution of Heifetz's (1994) work that begins to engage us more specifically in issues of time, especially in near and distant time, is the concept of adaptive work. The challenges we see in near and distant time are frequently what Heifetz (1994) defines as adaptive challenges - those that require new learning, changes in values and behavior, and adjustments from numerous places within a system. In adaptive work it is not just the path to the solution that is unknown, but often the problem itself does not have a specific and singular definition (Heifetz, 1994). In many ways, these adaptive challenges are similar to Grint's (2010) notion of wicked problems- those that are intractable, novel, and/or so complex in nature they cannot be disentangled from the broader environmental contexts in which they exist. If we challenge our notions of adaptive work as living merely in the near and distant future, we can begin to think about addressing these wicked challenges with an eye just not for our lifetimes, but for lifetimes to come. This is especially important when addressing leadership through a framework for sustainability and peace, as it is only when we truly begin to embrace distant and deep time that we can make the 
necessary substantial changes that will lead us towards stronger relationships with the world and each other.

\section{Systems, Chaos, and Complexity}

Another key concept in leadership studies that impacts sustainability greatly is the notion of systems and systems thinking. Systems thinking provides great space for enhanced reflection on time dimensions. In their prescient book, Systemic leadership: Enriching the meaning of our work, Allen \& Cherrey (2000) suggest that, "In a networked world, one’s value is measured by one’s connection to it. Our relationships need to model and keep pace with the nature of the system” (p. 8). If we listen, our social and natural systems are telling us quite clearly that we can no longer operate within a myopic framework of limited timescales if we wish to successfully respond to the leadership challenges of our time. Sustainability and the broader collection of wicked challenges, both social and ecological, have long histories and trailing impacts.

Through their work on systems thinking, Senge, et al. (2008) urge us to create our desired futures, while Scharmer (2009; 2013) provides us a framework for thinking about how we might use the emerging future to help us lead in the present. These notions try to help us better define the work that we do in the present, near, and distant time dimensions, and help us to operate among and between them, but our knowledge and experience has to date not enabled us to clearly consider the fourth time dimension- that of deep time. Deep time in these contexts can be what Plotkin (2008) discusses as experiencing our “...lives within much larger temporal contexts, nourishing a strong, felt connection with both past...” (p. 397) and “...a communion with the generations of the measureless future” (p. 438).

Some emerging thinking on eco-leadership (Senge et al., 2008; Satterwhite, 2010; 2012; Western, 2008) and the need to reconnect with indigenous and non-dominant teachings (Bordas, 2007) can begin to inform our notions about deep time in leadership studies - what it might look like and how it might be 
enacted - but as a whole this area requires much more work. Other emerging discourses like those presented by Wheatley (2006) and Wilber (2000) emphasize the importance of interconnectedness, collectivism, higher levels of consciousness, and seeing our world and the organizations in which we function as living, dynamic systems where deep order and resilience can arise from chaos and complexity.

In their work on complexity leadership, Uhl-Bien, Marion, and McKelvey’s (2007) identify a model of leadership rooted in many of the concepts discussed above, and suggest a new "paradigm for leadershipone that frames leadership as a complex interactive dynamic from which adaptive outcomes (e.g., learning, innovation, and adaptability) emerge” (p. 298). This model proposes that leadership be seen as a complex pattern of interactions within a system from which "a collective impetus for action and change emerges” (p. 299) and new patterns of behavior are established. Central to this model are what Uhl-Bien, et. al. (2007) identify as complex adaptive systems (CAS) within organizations, characterized by their adaptable structures, networks of relationships, and the capacity to evolve over time to create and respond to new information. This is also closely related to what Meadows (2008) describes as meta-resilient, selforganizing systems, or systems that feature “feedback loops that can learn, create, design, and evolve ever more complex restorative structures.” (p. 76).

These discourses implore us to seek greater connection with the complex systems and dynamics of which we are a part (Satterwhite, et. al., 2015). As we move to integrate deep and distant time into our view of leadership we will need to consider how we prepare future generations to take up and work within such vast and ambiguous boundaries. The emerging constructs of leadership discussed above are beginning to inform approaches to leadership development and education where learners are challenged to grapple with complexity and uncertainty, and thus provide supportive spaces to do this work. As we strive to better understand our relationship with time, and engage particularly with the notion of distant and deep histories and futures, we must also build this perspective into our leadership development and education 
programs to be more in line with the notions of sustainability and peace. Leadership development and education programs must engage with these notions and connect learners with practical examples and theoretical constructs that will enable them to begin to fathom the impact of deep time on leadership challenges. We must engage with the teaching of indigenous peoples who have long connected with a broader sense of time than dominant Western constructs. We must learn lessons from the grand and the small, which contain the stories of our past and provide hints to our futures. We must challenge ourselves to move beyond the notion of short-term gains to multi-generational solutions. If we move to a framework of leadership grounded in the concepts of sustainability and peace, then we must, in turn, embrace a more nuanced and deepened sense of time that will serve to connect us not only with those who have come before us, but with those who will walk this planet long after we are gone. We prepare this place for them.

\section{References:}

Allen, K., and Cherrey, C. (2000). Systemic leadership: Enriching the meaning of our work. Lanham, Maryland: University Press of America.

Benford, G. (1999). Deep time: How humanity communicates across millennia. New York, NY: Avon Books.

Bordas, J. (2007). Salsa, soul, and spirit: Leadership for a multicultural age. San Francisco, CA: Berrett-Koehler. Boulding, K. (1966). The economics of the coming spaceship earth. In H. Jarrett (Ed.), Environmental quality in a growing economy: Essays from the sixth resources for the future forum, pp. 11-22. Baltimore, MD: Johns Hopkins University Press.

Capra, F., and Luisi, P. L. (2014). The Systems view of life: A unifying vision. Cambridge, UK: Cambridge University Press.

Frederick, S., Loewenstein, G., and O’Donoghue, T. (2002). Time discounting and time preference: A Critical review, Journal of Economic Literature, XL, pp. 351-401.

Grint, K. (2010). Leadership: A very short introduction. Oxford, UK: Oxford Press.

Gould, S. J. (1987). Time’s arrow, time's cycle: Myth and metaphor in the discovery of geological time. Cambridge, Mass: Harvard University Press. 
Heifetz, R. (1994). Leadership without easy answers. Cambridge, MA: Harvard University Press.

Meadows, D. (2008). Thinking in systems: A Primer. White River Junction, VT: Chelsea Green.

Murphy, S., and Riggio, R. (2003). The future of leadership development. Mahaw, NJ: Lawrence Erlbaum Associates.

Plotkin, B. (2008). Nature and the human soul: Cultivating wholeness and community in a fragmented world. Novato, CA: New World Library.

Satterwhite, R. (2010). Deep systems leadership: A model for the 21st century. In B. Redekop (Ed.), Leadership for environmental sustainability (pp. 230-247). New York \& London: Routledge.

Satterwhite, R. (2012). Halting the decline: How leadership theory and practice can address global biodiversity loss. In D. Gallagher (Ed.), Environmental leadership: A reference handbook (pp. 577-585). Los Angeles, CA: SAGE.

Satterwhite, R., McIntyre Miller, W., and Sheridan, K. (2015). Leadership for sustainability and peace: Responding to the wicked challenges of the future. In Sowcik, M., Andenoro, A., McNutt, M., and Murphy, S. E. (Eds.), Leadership 2050: Critical challenges, key contexts, and emerging trends (pp.59-74). Bingley, UK: Emerald.

Scharmer, O. (2009). Theory U: Leading from the future as it emerges. San Francisco, CA: Berrett-Koehler.

Scharmer, O., and Kaufer, K. (2013). Leading from the emerging future: From ego-system to eco-system economies. San Francisco, CA: Berrett-Koehler.

Senge, P., Smith, B., Kruschwitz, N., Laur, J., and Schley, L. (2008). The necessary revolution: How individuals and organizations are working together to create a sustainable world. New York, NY: Doubleday.

Smail, D. L. (2008). On Deep History and the Brain. Berkeley, CA: University of California Press.

Uhl-Bien, M., Marion, R., and McKelvey, B. (2007) Complexity leadership theory: Shifting leadership from the industrial age to the knowledge era, The Leadership Quarterly, 18:4, pp. 298-318

Western, S. (2008). Leadership: A critical text. Los Angeles, CA: SAGE.

Wheatley, M. (2006). Leadership and the new science. San Francisco, CA: Berrett-Koheler.

Wilber, K. (2000). A theory of everything: An integral vision for business, politics, science and spirituality. Boston, MA: Shambhala Publications.

Wilson, E. O. (2014). The meaning of human existence. New York, NY: Liveright Publishing. 


$$
\text { of }
$$

